TAO, Vol. 17, No. 1, 317-327, March 2006

\title{
NOTES AND CORRESPONDENCE \\ Long-Term Mean Vertical Wind Observed by the Chung-Li VHF Radar
}

\author{
Jenn-Shyong Chen ${ }^{1, *}$
}

(Manuscript received 9 September 2004, in final form 1 December 2005)

\begin{abstract}
Plenty of observations using VHF/UHF radars worldwide have shown that long-term average vertical winds are downward in the middle troposphere and slightly upward in the lower stratosphere. The Chung-Li VHF radar $\left(121.1^{\circ} \mathrm{E}, 24.9^{\circ} \mathrm{N}\right)$, however, hasn't yet given any report on this issue; in this note we present such observations. Monthly averages show that in the wintertime (from November to February) the vertical velocities were biased to negative values below the jet-stream wind maximum and had magnitudes in excess of $0.5 \mathrm{~m} \mathrm{~s}^{-1}$ sometimes, which is larger than most other radar observations. In the warm period, however, the vertical velocities were mostly close to zero. In addition, wavelike structures in the profiles of vertical velocities were observed in the lower stratosphere and in the troposphere, respectively, in the wintertime and in two months of the warm period. Many of the vertical velocity profiles presented here are similar to previous observations made with other VHF radars.
\end{abstract}

(Key words: Vertical wind bias, Chung-Li VHF radar, Jet stream, Gravity wave)

\section{INTRODUCTION}

Vertical wind is an important meteorological variable due to its close connection with upward/downward transportation of energy, heat, moisture, momentum, ozone, and so forth. VHF/UHF wind-profiling radars are probably the best at measuring vertical wind, with high

\footnotetext{
${ }^{1}$ Department of Computer and Communication Engineering, Chienkuo Technology University, Changhua, Taiwan, ROC

* Corresponding author address: Prof. Jenn-Shyong Chen, Department of Computer and Communication Engineering, Chienkuo Technology University, Changhua, Taiwan, ROC;

E-mail: jschen@ctu.edu.tw
} 
temporal and spatial resolutions. Many observations using VHF/UHF radars have shown that mean vertical winds are downward in the middle troposphere and are usually slightly upward in the lower stratosphere (e.g., Fukao et al. 1991; Gage et al. 1991; Yoe and Rüstter 1992; Nastrom et al. 1994; McAfree et al. 1995). Extra reversals of vertical wind, that is, upward in the lower troposphere (below $3 \mathrm{~km}$ ) and downward in the deeper stratosphere, have also been verified (Worthington 1999; Worthington et al. 2001). Reversal of vertical wind may also be found in the middle troposphere at the tropical zone (Jagannadha Rao et al. 2002). A few models have been proposed for the observations, for example, slope of isentropic surface (Fukao et al. 1991), convection and radiative balance in the tropics (Gage et al. 1991), vertical-wind circulation linked to the jet stream (Yoe and Rüstter 1992), gravity-wave activity (Nastrom and VanZandt 1994 1996), downward hydrometeors (McAfee et al. 1995), slight tilt of vertical radar beam (Huaman and Balsley 1996), Kelvin-Helmholtz instability (Muschinski 1996), mountain wave pattern (Worthington et al. 2001), monsoon circulation (Jagannadha Rao et al. 2002), and incoherent averaging of Doppler spectra (Muschinski 2004).

As one of the wind-profiling radars between tropical and midlatitudinal zones, the ChungLi VHF radar $\left(121.1^{\circ} \mathrm{E}, 24.9^{\circ} \mathrm{N}\right.$, Taiwan) hasn't yet given any report on the long-term average of vertical wind. In this note, we present some results for the above issue. In addition to vertical and horizontal winds, some parameters such as spectral width, standard deviation of the vertical velocities, and horizontal correlation length of the refractivity irregularities, were also examined, in which the last parameter is less discussed in the literature of VHF/UHF radars (Hocking 1985; Pan and Liu 1992; Chen et al. 1997). These parameters can provide some useful information on the atmospheric conditions responsible for the bias in the vertical velocities. Preliminary results and qualitative discussion are presented in this paper.

\section{RADAR DATA AND WIND MEASUREMENT}

The radar data were collected in the years of 1995 - 2001, observed by the Chung-Li VHF radar, with vertical radar beam and pulse lengths of $2 \mu \mathrm{s}$ and $4 \mu \mathrm{s}$. Sampling time was $0.1-0.5 \mathrm{~s}$. Many of the observations were operated with three receiving channels so that the method of spaced antenna (SA) can be utilized to derive the horizontal wind. Figure 1 shows the statistic of observational days and hours, in which the data with precipitation are not included.

Vertical velocity of the atmosphere can be estimated by the mean Doppler frequency $\left(f_{d}\right)$ of the vertical radar beam, $-f_{d} \lambda / 2$, where $\lambda$ is the transmitted wavelength. For the SA method used for retrieving horizontal wind, a few expressions have been derived under various assumptions and conditions (e.g., Meek 1980; Briggs 1984; Liu et al. 1990; Pan and Liu 1992). This study employed algorithms referring to Briggs (1984). Although horizontal wind can be obtained by using more sophisticated SA algorithms (Doviak et al. 1996; Holloway et al. 1997) or other approaches such as structure function (Praskovsky and Praskovskaya 2003), the estimated horizontal wind here is adequate to the purpose of this study. A calibration between the horizontal winds measured, respectively, by rawinsonde and radar was also made to verify the radar result. After using the thresholds of SNR $>1$ and wind magnitude $<100 \mathrm{~m} \mathrm{~s}^{-1}$ for the radar data, the two sets of horizontal winds are in reasonable agreement, as shown inFig. 2. 
As for the horizontal correlation length of the refractivity irregularities, which was also examined in this study, it can be estimated using the equations developed by Pan and Liu (1992).
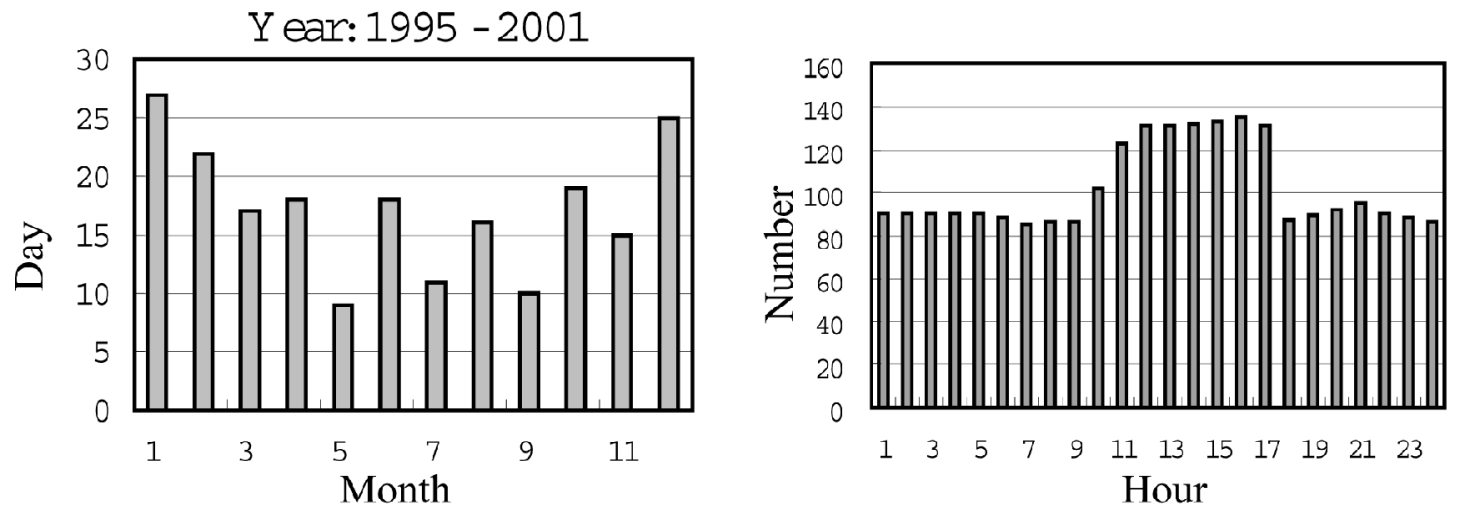

Fig. 1. Statistic of observational days and hours. The data with precipitation are not included.

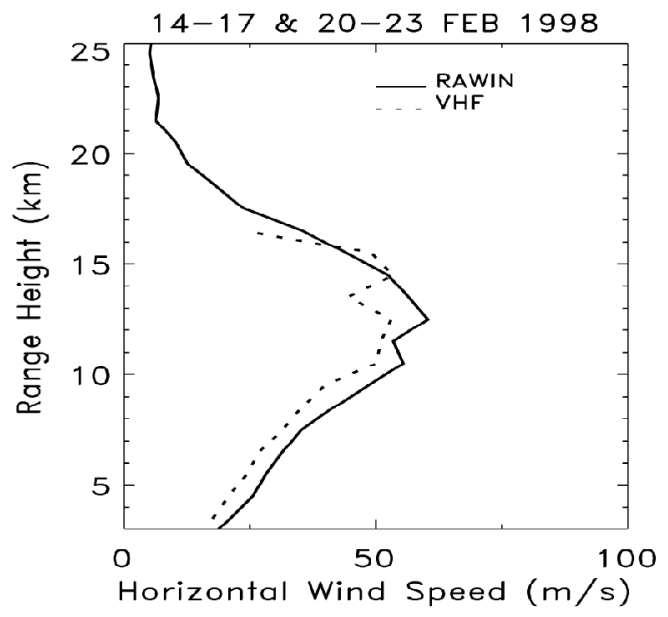

Fig. 2. Horizontal wind speeds measured by Pan-Chiao rawinsonde (solid) and Chung-Li VHF radar (dash). The distance between the two stations is $\sim 30 \mathrm{~km}$. 


\section{RESULTS AND DISCUSSIONS}

\subsection{Radar Beam-Pointing Inaccuracy}

Considering that slight inaccuracy of vertical radar beam can induce a biased vertical velocity (Human and Balsley 1996), we examined this issue before showing the wind data. Such bias arises from the component of horizontal wind projecting on the direction of the slanted radar beam. Accordingly, both directions of the slanted radar beam and the horizontal wind determine a negative or positive bias. We discuss this by referring to Fig. 3 (observed in June 2000, between the heights of $3-11 \mathrm{~km}$ ). As shown, the horizontal winds came from all directions; nevertheless, the vertical velocities were nearly zero irrespective of the direction of horizontal wind. If the vertical radar beam is indeed pointed inaccurately, the vertical velocity should be biased to positive and negative values, respectively, at two opposite wind directions. However, such a feature is not seen in Fig. 3. In view of this, the vertical radar beam should be directed quite accurately.

\subsection{Monthly Averages}

Figure 4 shows the monthly averaged profiles of vertical velocities and horizontal wind speeds for the radar data observed, respectively, with $4-\mu$ s and $2-\mu$ s pulse lengths. The mode of $2-\mu \mathrm{s}$ pulse length observed only the heights below $\sim 14 \mathrm{~km}$, but the mode of $4-\mu \mathrm{s}$ pulse length reached the lower stratosphere. As seen, in the wintertime (from November to February)

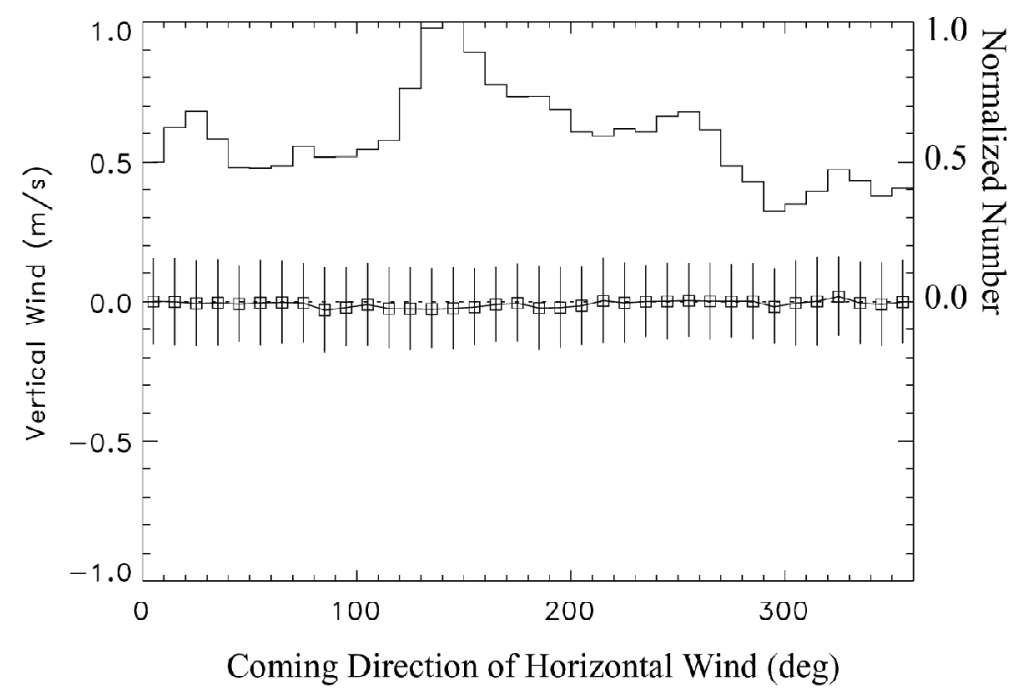

Fig. 3. Normalized histogram of horizontal wind directions (curve) and mean vertical velocities (square), observed in June 2000, between $3-11 \mathrm{~km}$. Vertical error bars indicate the standard deviations of vertical velocities. 
Pulse Length: $4 \mu \mathrm{s}$

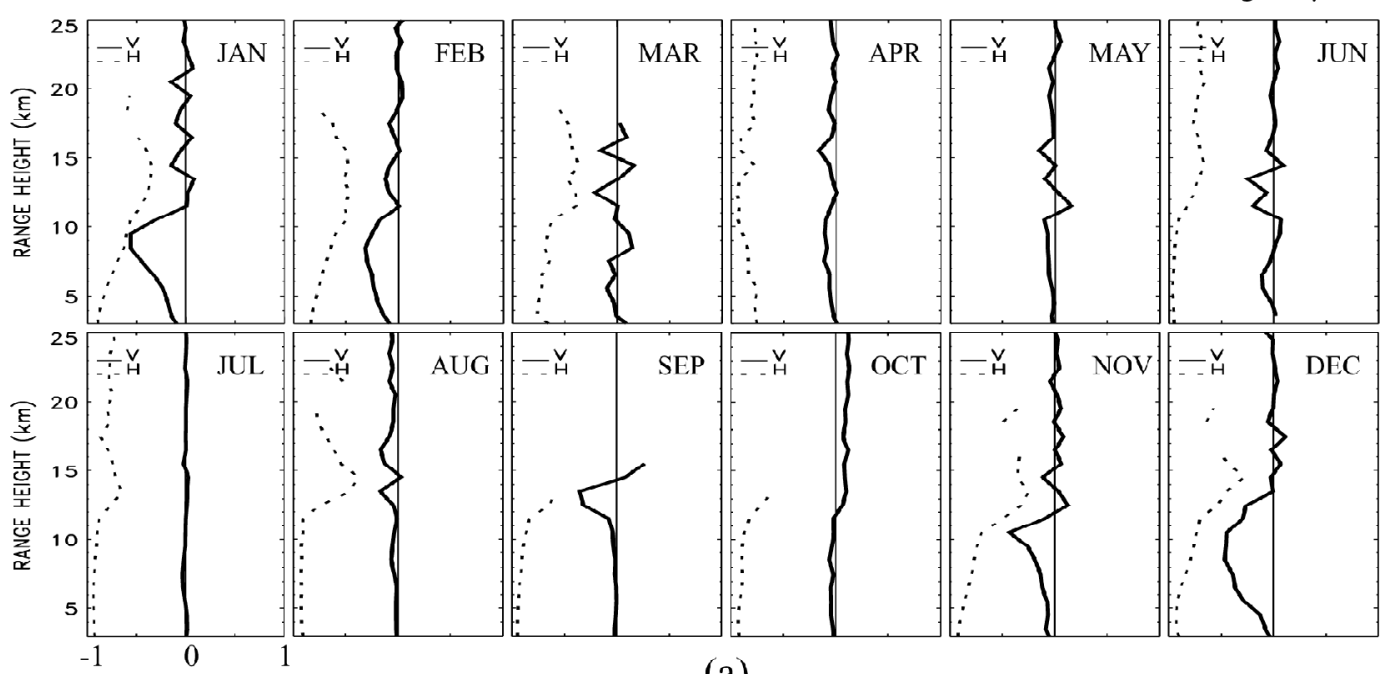

Vertical Wind $(\mathrm{m} / \mathrm{s})$

(a)

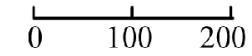

IIorizontal Wind Speed $(\mathrm{m} / \mathrm{s})$

Pulse Length: $2 \mu \mathrm{s}$

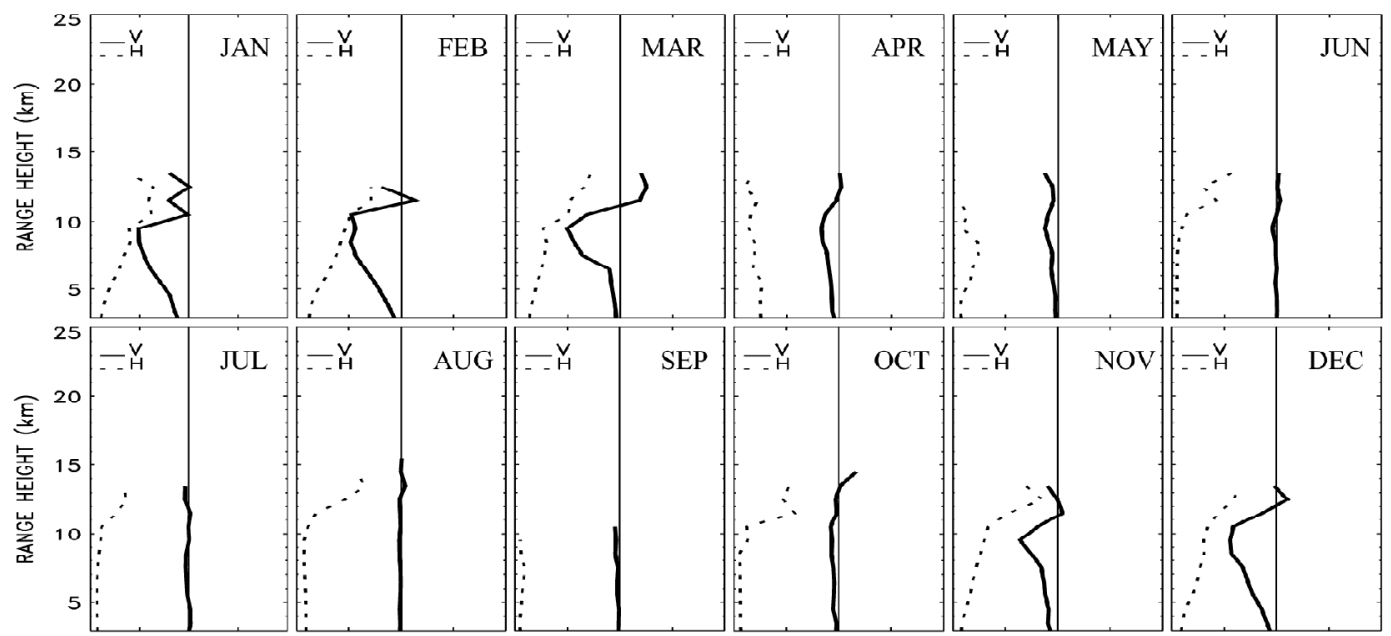

(b)

Fig. 4. Monthly averaged profiles of vertical velocities (solid) and horizontal wind speeds (dash). (a) and (b) display the data of $4-\mu \mathrm{s}$ and $2-\mu \mathrm{s}$ pulse lengths, respectively. 
large negative vertical velocities occurred below the height of $\sim 11 \mathrm{~km}$. The same feature also appeared in March of 2- $\mu$ s mode but was not seen in March of the 4- $\mu$ s mode. The most negative values were in excess of $0.5 \mathrm{~m} \mathrm{~s}^{-1}$ and located at $\sim 9 \mathrm{~km}$. In the same period, the jet stream indicated by the horizontal wind speed was situated between $12 \mathrm{~km}$ and $15 \mathrm{~km}$ and had the largest speed at over $50 \mathrm{~m} \mathrm{~s}^{-1}$. Another case with large negative vertical velocity appeared in September of the 4- $\mu$ s mode; however, its most negative value located at higher altitude than those in the wintertime. Except for the case in September, vertical velocities of the 4- $\mu \mathrm{s}$ mode were less biased in the warm period (from April to October) than in the wintertime. A difference between the horizontal winds in the warm period and wintertime can also be identified, that is, the wind speed and wind shear below the jet-stream wind maximum are larger in the wintertime. It seems that larger horizontal wind and wind shear lead to more negative vertical velocity. Muschinski (1996) provided a potential model to interpret this relationship, namely, the asymmetrically tilted quasi-specular layers due to the Kelvin-Helmholtz instability (KHI). This model indicates negative and positive biases of vertical velocities, respectively, below and above the jet-stream wind maximum; moreover, the magnitude of vertical velocity bias is proportional to the magnitude of wind shear. In Fig. 4, however, positive vertical winds above the jet-stream wind maximum were unremarkable in the wintertime. Exceptional cases are seen in September and October of Fig. 4a and in March of Fig. 4b, which show an observable reversal of vertical wind around the height of jet-stream wind maximum. Although not very definitely, the wind profiles in some months (e.g., Jan., Nov., and Dec. of Fig. 4a) show that the wind shears above the jet-stream wind maximums were smaller than those below. Moreover, the aspect sensitivity is commonly stronger in the stratosphere (above the height of jet-stream wind maximum) than in the troposphere (one evidence is shown in Fig. 6, mentioned later), this, according to Muschinski (1996) again, can also lead to a smaller magnitude of vertical wind bias in the stratosphere. In addition, we noted the wavelike structures in the profiles of vertical velocities above the jet-stream wind maximum in the wintertime, which could be due to some short-wavelength, up-propagating gravity waves originating from the strong jet streams. The short-wavelength, up-propagating gravity waves might disturb the tilted quasi-specular layers resulting from the KHI, reducing the effect of the KHI on the vertical velocity. More investigations can be executed for this topic.

The KHI model also predicts a proportional bias of vertical velocity to the square of radar beam width. As compared with other VHF radars' observations, for example, $\sim 1 \mathrm{~cm} \mathrm{~s}^{-1}$ in Pohnpei, $\sim-20 \mathrm{~cm} \mathrm{~s}^{-1}$ in Gadanki, $\sim-20 \mathrm{~cm} \mathrm{~s}^{-1}$ in MU, $\sim-6 \mathrm{~cm} \mathrm{~s}^{-1}\left(\sim 20 \mathrm{~cm} \mathrm{~s}^{-1}\right.$ in some cases) in Platteville, $\sim-50 \mathrm{~cm} \mathrm{~s}^{-1}$ in SOUSY, the maximum biases of vertical velocities, $-40 \mathrm{~cm} \mathrm{~s}^{-1}$ to $-60 \mathrm{~cm} \mathrm{~s}^{-1}$, shown in Fig. 4 are quite large, except for beside the SOUSY result. The beam width of the Chung-Li radar is $\sim 7.4^{\circ}$, which is also larger than others (the aforementioned radars have the beam widths of $\sim 2.1^{\circ}, \sim 3^{\circ}, \sim 3.6^{\circ}, \sim 3.6^{\circ}$, and $\sim 5^{\circ}$, respectively). In view of this, broader radar beams indeed observe more negative vertical velocity.

More models and explanations for the biases in the vertical velocities have been proposed, as mentioned in the introduction (or see Worthington et al. 2001, for an overview). Among them, the mountain-wave model proposed by Worthington et al. (2001) predicts a further reversal of vertical velocity from positive to negative in the deeper stratosphere and from 
negative to positive in the lower troposphere $(<3 \mathrm{~km})$. Because of the limited heights observed, we cannot find a clue for the mountain wave effect from the present data. On the other hand, the role of up-propagating gravity wave is worth examining here. Nastrom and VanZandt $(1994,1996)$ argued that upward energy propagation gravity waves, which have downward phase propagation, could lead to negative bias in the vertical velocity. The up-propagating gravity waves may arise from orographic effect or instability in the planetary boundary layer, and their amplitudes grow with altitude and then increase the negative bias in the vertical velocity. The gravity waves may mostly stop at some critical level due to saturation processing and then break into turbulence. This scenario seems to be also one possibility for the deeply negative vertical velocities in the wintertime shown in Fig. 4. In the Chung-Li radar area, the winds in the lower troposphere are usually larger in the wintertime than in other months, which may produce stronger up-propagating gravity waves related to orographic effect or instability in the planetary boundary layer. The strong jet streams situated between $12 \mathrm{~km}$ and $15 \mathrm{~km}$ could provide possible critical levels for blocking the up-propagating gravity waves arising from the lower troposphere.

Wave activity can be further indicated by the standard deviation of vertical velocities and the spectral width. As shown in Fig. 5, between $6 \mathrm{~km}$ and $10 \mathrm{~km}$, the standard deviations of vertical velocities (left panel) and the spectral widths (right panel) in the wintertime (from November to February), where the vertical velocities were more negatively biased, were obviously larger than those in the other period, indicating more active waves in the wintertime. This infers that the gravity waves, proposed by Nastrom and VanZandt $(1994,1996)$, contribute part bias to the vertical velocity.

Another useful parameter but rarely examined is the horizontal correlation length of refractivity irregularities. As known, longer horizontal correlation length indicates a more stable atmosphere having stronger aspect sensitivity. Using the equations developed by Pan and Liu (1992), we estimated this parameter for respective receiver pairs. The mean profiles of this parameter, indicated as $l_{x}$, are displayed in Fig. 6a. As shown, the values of $l_{x}$ were around $25 \mathrm{~m}$ in the troposphere (below $11 \mathrm{~km}$ ) and increased gradually to $\sim 50 \mathrm{~m}$ in the stratosphere (above $15 \mathrm{~km}$ ). The transitional region was between $11 \mathrm{~km}$ and $15 \mathrm{~km}$, corresponding to the height interval of horizontal wind maximum. The order of $l_{x}$ is basically consistent with that given by Hocking (1985) but is closer to the buoyancy region. This result demonstrates that the atmosphere has stronger aspect sensitivity in the stratosphere than in the troposphere, although it is expected. Figure $6 \mathrm{~b}$ shows the monthly averages of $l_{x}$. As shown, on average the magnitude of $l_{x}$ between $5 \mathrm{~km}$ and $10 \mathrm{~km}$ was smaller in the wintertime, indicating a more turbulent middle troposphere in the wintertime. The turbulent middle troposphere could arise from strong horizontal wind and large wind shear, or active gravity waves. As a result, smaller $l_{x}$ corresponds to more negative vertical velocity.

Finally, one more noticeable feature is the wave like structures in the profiles of vertical velocities in the troposphere, as seen in March and June of the $4-\mu$ s mode. The vertical wavelength is about $6 \mathrm{~km}$, which is longer than that in the lower stratosphere during the wintertime. Jagannadha Rao (2002) reported on similar observation in the tropics and attributed it to the strong monsoon circulations that prevail half of the year in India. In view of this, similar circulation or convection might be responsible for the wave structures seen here. 

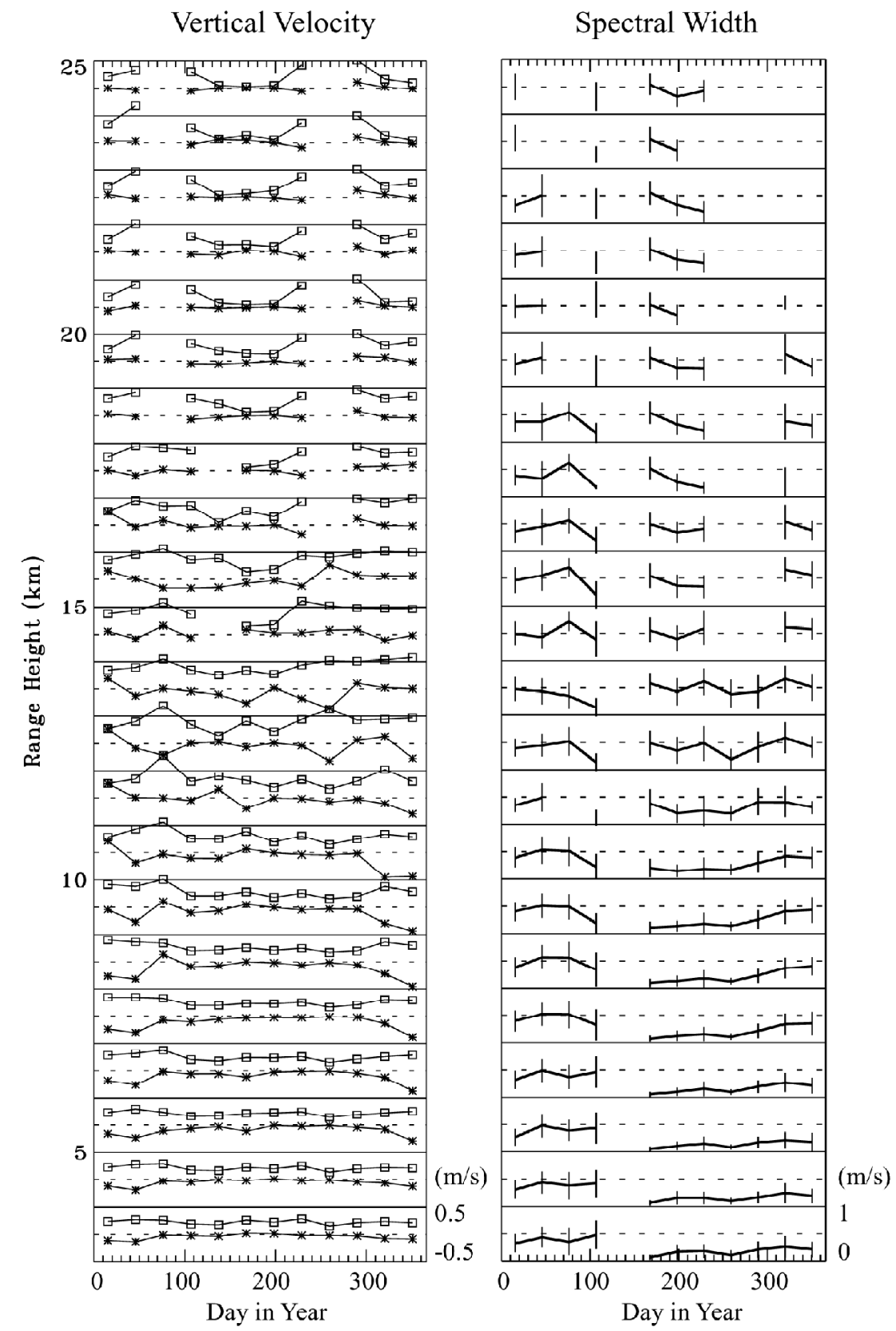

Fig. 5. Monthly averages of vertical velocities (asterisk), standard deviations of vertical velocities (square), and spectral widths (right panel) at different heights. Vertical error bars indicate the standard deviations of spectral widths. 

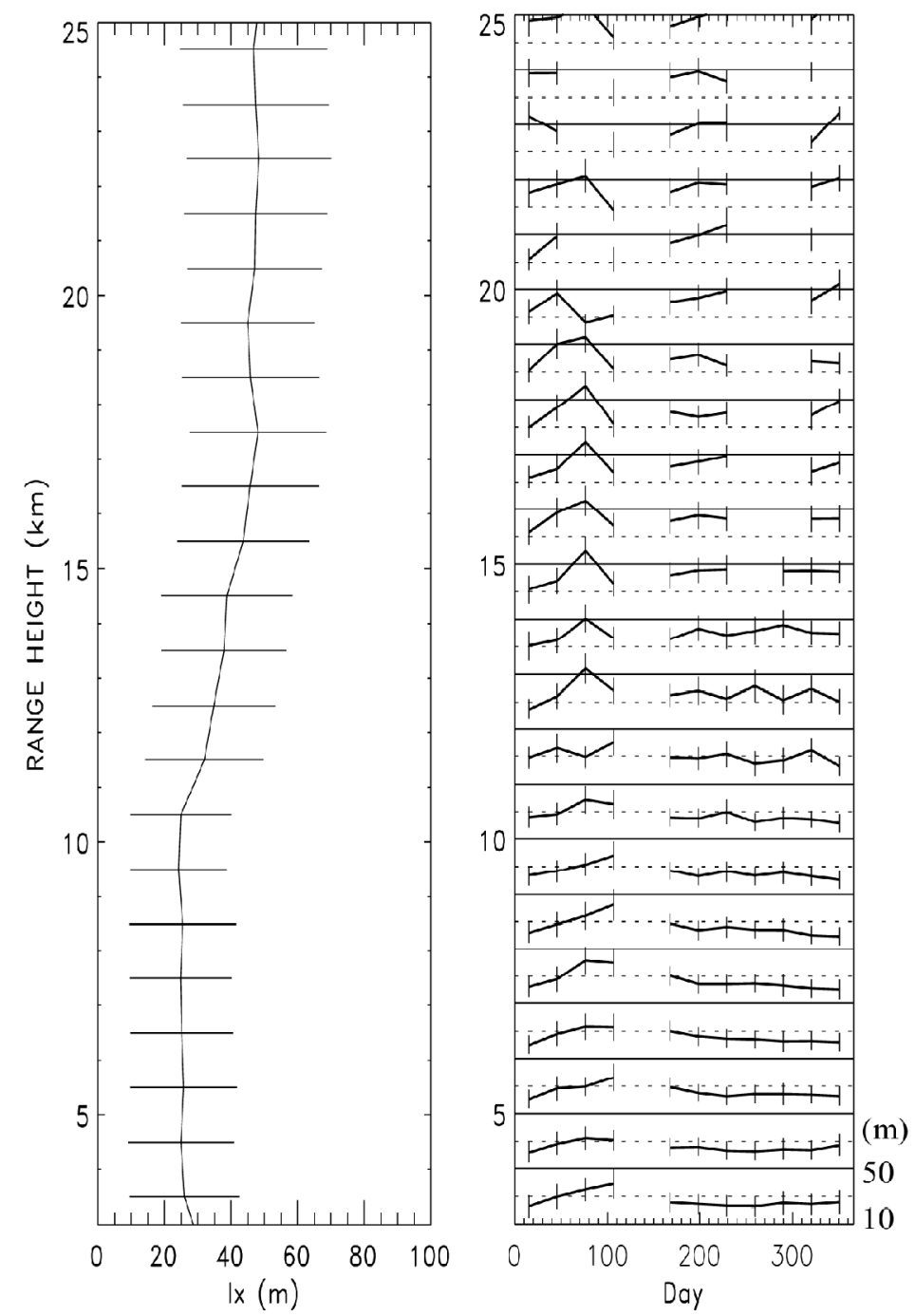

Fig. 6. Means of horizontal correlation lengths of the refractivity irregularities: profile (left panel) and monthly averages at different heights (right panel). Both horizontal and vertical error bars indicate the standard deviation.

\section{SUMMARY AND CONCLUSIONS}

The Chung-Li radar has observed some characteristics of the atmospheric vertical wind seen in tropics and midlatitudes. This could be due to the subtropical position of the radar site and the unique location of Taiwan area; in this area distinguishing weather systems prevail in different seasons. The largest negative vertical velocities were observed to be $-0.4 \mathrm{~cm} \mathrm{~s}^{-1}$ to $-0.6 \mathrm{~m} \mathrm{~s}^{-1}$, which are larger than most of VHF radar observations, and appeared just below the 
horizontal wind maximum in the wintertime (from November to February), which is similar to the observations at midlatitudes (e.g., the SOUSY and MU radars). Reversal of vertical velocity around the horizontal wind maximum was observed sometimes but was not remarkable in the wintertime. The KHI and wind shear, and up-propagating gravity waves, proposed by Muschinski (1996) and Nastrom and VanZandt (1994, 1996), respectively, could be two of the factors responsible for the large negative vertical velocities observed here. Moreover, wavelike structures in the profiles of vertical velocities in the troposphere were seen in two months of the warm period; a similar feature has been observed in the tropics (Gadanki, India). The effect of mountain waves on the vertical velocity (Worthington et al. 2001) cannot be examined from the present data, but it is worth studying with proper radar parameters for the Chung$\mathrm{Li}$ radar in the future, considering the mountains nearby are as high as $1000-3000 \mathrm{~m}$.

Acknowledgements This paper was supported by the National Science Council of the Republic of China (Taiwan), under Grants NSC93-2111-M-270-001 and NSC94-2111-M-270001. The Chung-Li VHF radar is maintained by the Institute of Space Science, National Central University, Taiwan. The author collected most of the radar data during his postdoctoral research in the Institute of Space Science and would like to express great appreciation to Prof. Yen-Hsyang Chu for encouraging the research.

\section{REFERENCES}

Briggs, B. H., 1984: The analysis of spaced sensor records by correlation techniques. Handbook for MAP, 13, 166, SCOSTEP Secr., Univ. of Ill., Urbana.

Chen, J. S., J. Y. Liu, and Y. H. Chu, 1997: Effects of anisotropy and power spectrum of refractivity irregularities on determination of layer thickness and layer position using the frequency domain interferometry technique. Radio Sci., 32, 437-451.

Doviak, R. J., R. J. Lataitis, and C. L. Holloway, 1996: Cross correlations and cross spectra for spaced antenna wind profilers, 1, Theoretical analysis. Radio Sci., 31, 157-158.

Fukao, S., M. F. Larsen, M. D. Yamanaka, H. Furukawa, T. Tsuda, and S. Kato, 1991: Observations of a reversal in long-term average vertical velocities near the jet stream wind maximum. Mon. Wea. Rev., 119. 1479-1489.

Gage, K. S., J. R. McAfee, D. A. Carter, W. L. Ecklund, A. C. Riddle, G. C. Reid, and B. B. Balsley, 1991: Lont-term mean vertical motion over the tropical Pacific: Wind-profiling Doppler radar measurements. Science, 254, 1771-1773.

Hocking, W. K., 1985: Measurement of turbulence energy dissipation rates in the middle atmosphere by radar technique: A review. Radio Sci., 20, 1403-1422.

Holloway, C. L., R. J. Doviak, S. A. Cohn, R. J. Lataitis, and J. S. V. Van Baelen, 1997: Cross correlations and cross spectra for spaced antenna wind profilers, 2, Algorithms to estimate wind and turbulence. Radio Sci., 32, 967-982.

Huaman, M., B. B. Balsley, 1996: Long-term average vertical motions observed by VHF wind profilers: The effect of slight antenna pointing inaccuracies.J. Atmos. Oceanic Tech., 13, 560-569. 
Jagannadha Rao, V. V. M, M. Venkat Ratnam, and D. Narayana Rao, 2002: Study of mean vertical motions over Gadanki $\left(13.5^{\circ} \mathrm{N}, 79.2^{\circ} \mathrm{E}\right)$, a tropical station, using Indian MST radar. Radio Sci., 37, 1108, doi:10.1029/2001RS002505.

Liu, C. H., J. Röttger, C. J. Pan, and S. J. Franke, 1990: A model for spaced antenna observational mode for MST radars. Radio Sci., 25, 551-564.

McAfee, J. R., K. S. Gage, and R. G.. Strauch, 1995: Vertical velocities at Platteville, Colorado: An intercomparison of simultaneous measurements by the VHF and UHF profilers. Radio Sci., 34, 1027-1042.

Meek, C. E., 1980: An efficient method for analyzing ionospheric drifts data.J. Atmos. Terr. Phys., 42, 835-839.

Muschinski, A., 1996: Possible effect of Kelvin-Helmholtz instability on VHF radar observations of the mean vertical wind. J. Appl. Meteor., 35, 2210-2217.

Muschinski, A., 2004: Local and global statistics of clear-air Doppler radar signals. Radio Sci., 39, 1008, doi:10.1029/2003RS002908.

Nastrom, G. D., and T. E. VanZandt, 1994: Mean vertical motions seen by radar wind profilers. J. Appl. Meteor., 33, 984-995.

Nastrom, G. D., and T. E. VanZandt, 1996: Biases due to gravity waves in wind profiler measurements of winds. J. Appl. Meteor., 35, 243-257.

Pan, C. J., and C. H. Liu, 1992: A model for oblique spaced antenna technique for mesosphere-stratosphere-troposphere radars and its applications. Radio Sci., 27, 131-144.

Praskovsky, A. A., and E. A. Praskovskaya, 2003: Structure-function-based approach to analyzing received signals for spaced antenna radars. Radio Sci., 1068, doi:10.1029/ 2001RS002544.

Worthington, R. M., 1999: Calculating the azimuth of mountain waves, using the effect of tilted finescale stable layers on VHF radar echoes. Ann. Geophys., 17, 257-272.

Worthington, R. M., A. Muschinski, and B. B. Balsley, 2001: Bias in mean vertical wind measured by VHF radars: Significance of radar location relative to mountains.J. Atmos. Sci., 58, 707-723.

Yoe, J. G., and R. Rüster, 1992: VHF Doppler radar observations of vertical velocities in the vicinity of the jet stream. Mon. Wea. Rev., 120, 2378-2382. 